\title{
Use of the Mar-Lin Criteria to Determine the Influence of Porosity on the Iosipescu and Short Beam Shear Properties in Carbon Fiber Polymer Matrix Composites
}

\author{
Antonio Carlos Ancelotti Junior ${ }^{2 *}$, Luiz Claudio Pardini ${ }^{\mathrm{b}}$, Eduardo Marcelo Bezerra ${ }^{\mathrm{a}}$, Dennis Roach \\ anstituto Tecnológico de Aeronáutica - ITA, \\ Praça Marechal Eduardo Gomes, 50, Vila das Acácias, \\ 12228-900 São José dos Campos, SP - Brazil \\ ${ }^{\mathrm{b}}$ Centro Técnico Aeroespacial - CTA, Instituto de Aeronáutica e Espaço, \\ Divisão de Materiais - AMR 12228-904 São José dos Campos, SP - Brazil \\ 'Sandia National Laboratories, FAA Airworthiness Assurance Center - NM 87185 \\ Albuquerque - USA
}

Received: September 1, 2009; Revised: November 23, 2009

\begin{abstract}
To address a critical aspect of the fast growing use of composites in aircraft and aerospace industry, the influence of the porosity on the shear strength of composites property was investigated as a mean for determining the critical values of porosity. Acid digestion techniques were applied to determine the void volume ratio of two families of carbon epoxy laminates ( 8 and 16 plies). Ultrasonic inspections revealed the corresponding attenuation coefficients. The void morphology was investigated by optical microscopy. Results from Interlaminar shear and Iosipescu shear tests were correlated with the attenuation coefficient to determine critical values of porosity using a modified Mar-Lin fracture criteria. It has been shown that the shear strength decrease with the increase of void volume ratio and the effects are more significant in thicker laminates. This work showed that by using the MarLin criteria the singularity order, which is an indicative of the sensibility to voids in composites, is dependent of type of loading and void distribution.
\end{abstract}

Keywords: carbon epoxy composites, porosity, mechanical testing, optical microscopy

\section{Introduction}

In the past few years high performance composites usage in aeronautical and aerospace industries has increased sharply. These materials have large application into manufacturing of primary aircraft structures (like rudder, aileron, flaps, fuselage and others) due the high specific strength and modulus, excellent fatigue life and the ability to be tailored to meet specific, directional strength requirements ${ }^{1,2}$.

Porosity has been a common and persistent quality problem or defect found in the manufacturing process of composite parts. The increase in the applications of composite materials suggests a need to also improve the quality control in the manufacturing process of a structural part since the final properties of the material are directly influenced by the presence of defects such as porosity and delamination ${ }^{3}$. These defects threaten composite performance. Generally, porosity is concentrated in between composite laminae (plies) as air pockets are entrapped preferentially in the rich resin areas that are dispersed across the thickness of the laminate. Several factors can contribute to the void formation such as the chemical resin composition, type and orientation of the reinforcement, the number of plies, the number of bleeder cloth layers used in the molding process, humidity, cure pressure variation, cure temperature variation, leakage of the vacuum bag during the cure process, tooling leakage, bad positioning of vacuum points in the tooling and others ${ }^{4}$. However, among the exposed factors, the cure pressure variation is the primary factor that affects the integrity of composite parts in aircraft components. Several papers have shown that the cure pressure variations influence the compaction of the plies during the cure process, resulting in composite laminates with porosity ${ }^{5,6,7}$. Bowles and Frimpong ${ }^{5}$ studied the influence of pressure in the composite properties and void formation while correlating their experimental results with theoretical models. Qualitative and quantitative nondestructive inspection techniques (NDI) techniques can be used to evaluate integrity of structural parts; however, the most common method applied on the aerospace industry is the ultrasonic inspection (UT) method. Internal pores in a structure scatter UT elastic waves which indicate attenuation levels. So, the ultrasonic inspection is an important technique for monitoring defects in composite aircraft parts. Several papers in the literature have showed that the results of ultrasonic inspection (in terms of attenuation coefficient) can be correlated with the void volume content of composite laminate ${ }^{7,9-12}$. The void content can be obtained by a destructive technique like acid digestion ${ }^{13}$ or optical and digital analysis ${ }^{14}$.

The shape and distribution of porosity are also important issues and they also influence mechanical properties. Stone and Clarke showed that most of the voids in unidirectional composites tend to be small, and have a spherical shape for void volume fraction below $1.5 \%$. For high void volume fractions the air pockets tend to be larger, slit-like and elongated ${ }^{9,15}$. The shape of the voids can differ according to fiber orientation and arrangement in the composite. For example, in bi-directional fabric composites the shape of voids can be spherical ${ }^{10}$, truncated elliptical cones ${ }^{4}$ and planar triangle format ${ }^{16}$.

Porosity and microcracks reduce mechanical properties of composite laminates. In particular, the matrix dominated properties, such as shear and compression strength are prone to significant 
reductions. Many researchers have been using the criteria provided by the Mar-Lin ${ }^{17}$ when dealing with the fracture tension for polymer composites having a notch ${ }^{18,19}$. The Mar-Lin criterion was then modified by Almeida et al. ${ }^{11}$ in order to study the effect of void content on composites using the ultrasonic attenuation coefficient as parameter instead of size of notches. Based on Mar-Lin equation, the critical volume fraction of voids for Interlaminar shear strength has been determined by many authors ${ }^{7-8,11-12,16}$ while no data can be found in the literature for considering critical void content for Iosipescu Shear.

The aim of the present work is to determine and compare critical void content, fracture toughness and the order of singularity of a bi-directional carbon/epoxy composite for Iosipescu shear and Interlaminar shear tests both based on the Mar-Lin criteria. The influence of composite thickness on the Mar-Lin criteria parameters was also investigated.

\section{Materials and Experiemental Procedure}

\subsection{Materials}

The composite laminate test specimens were manufactured by using the F584 pre-impregnated, carbon/epoxy fabric style 8HS (eigth Harness Satin), from Hexcel Composites. The 8HS fabric style resembles a $\left(0^{\circ}, 90^{\circ}\right)$ stacking. Two groups of composites laminates were manufactured, and named by $\mathrm{F}\left(0^{\circ}, 90^{\circ}\right)_{8}$ and $\mathrm{G}\left(0^{\circ}, 90^{\circ}\right)_{16}$ groups. Each composite type had four different levels of porosity. The lowest porosity level (Level 1 ) represents allowable porosity levels in composite laminate $(\sim 0.5 \%)$ and the highest porosity level (Level 4) represents unacceptable levels that must be quantified and assessed $(\sim 8 \%)$. The test specimens, for both Interlaminar and Iosipescu shear, were obtained from the same batch of raw material in order to avoid variability.

\subsection{Experimental methodology}

A schematic representation of the work methodology is presented in Figure 1. Composite test panels were manufactured using a vacuum bag/autoclave process. The porosity was induced in the composite laminate by varying the autoclave pressure ( 34 to $207 \mathrm{kPa}$ ) and also venting or not venting the vacuum bag during the curing process. The variation of cure pressure and vacuum bag venting were adopted as primary controls to induce porosity in the composite test panels because this accurately represents real problems that may occur during an autoclave fabrication of composite parts. The test panels were cured at $177^{\circ} \mathrm{C}$ by 2 hours minimum, following manufacturer recommended cure cycle. Test specimens for Interlaminar shear and Iosipescu shear test were obtained from a unique plate for each level of porosity. This was done to minimize the influence of the variation due raw material, fiber orientation, fiber volume, shape and size of pores in the Mar-Lin parameters, mainly in the order of singularity.

\subsubsection{Ultrasonic inspection}

The test panels were inspected by through-transmission ultrasonic method using a failure detector Reflectoscope $\mathrm{S} 80$ with $5 \mathrm{MHz}$ transmitter and receiver transducers type Automation X19625 and X19267 respectively. The ultrasound analysis generates color patterns which are related to the voltage signal generated in the emission transducer $\left(\mathrm{V}_{1}\right)$ and in the receptor transducer $\left(\mathrm{V}_{2}\right)$. The color scale obtained from the ultrasound analysis is related in turn to the voltage $(\mathrm{V})$ and the level of attenuation $(\mathrm{dB})$. The plates were placed on a rail to be inspected automatically by an Automation US640, C-scan water squirter system. The results were recorded and analyzed using the Robota software. Four test panels having different attenuation levels from each group were selected. The test specimens for Iosipescu shear

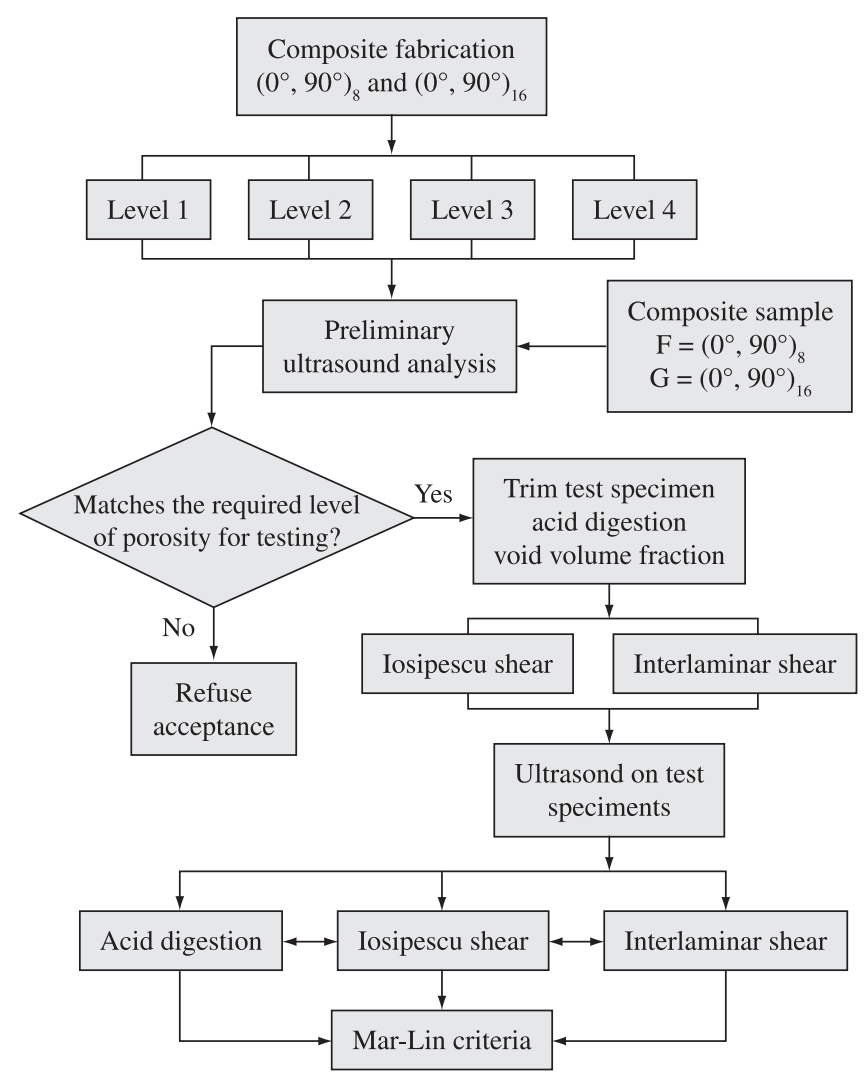

Figure 1. Schematic representation of the work methodology for manufacturing and testing composite test panels.

test, Interlaminar shear test and acid digestion test were re-inspected to refine the ultrasonic measurements. The results were used to calculate the attenuation coefficient which is given in $\mathrm{dB} \cdot \mathrm{mm}^{-1}$. The coefficient of attenuation $\alpha$ was determined according to Equation (1), where $t$ is the thickness of the sample.

$$
\alpha=\left(\frac{20 . \log \frac{V_{1}}{V_{2}}}{t}\right)
$$

\subsubsection{Void content determination}

The void content volume fractions were measured after ultrasonic inspections to correlate data from attenuation coefficient with mechanical measurements from the acid etch digestion technique. The void content was obtained from the average values of three samples measuring $30 \times 30 \mathrm{~mm}$ from each of the porosity groups according to the procedure described in the ASTM D3171 (13).

\subsubsection{Interlaminar shear strength test (ILSS)}

The composite specimens were tested for Interlaminar shear strength according to the ASTM D-2344 ${ }^{[20]}$. Ten specimens were tested for each group (F, G) and porosity level. Tests were performed in a universal testing machine EMIC DL 1000. The load span corresponded to a 4:1 span-to-thickness relation. The Interlaminar Shear Strength was calculated through Equation (2), where $P$ is the failure load, $t$ is the thickness and $w$ is the width of the specimen. The values for failure loads are given in Newtons, and thickness and width are in millimeters. 


$$
\text { Interminar Shear }(M P a)=\frac{P}{(t)(w)}
$$

\subsubsection{Iosipescu shear test (IST)}

The Iosipescu Shear Strength Tests for $\mathrm{S}_{13}$ direction were performed according to the procedure described in ASTM D5379 ${ }^{[21]}$. The test specimen for Iosipecu, $\mathrm{S}_{13}$ direction, requires lamination of high number of plies to reach the specified thickness on test device, that would be very difficult to obtain considering the purpose of this study (evaluate and compare certain porosity levels). In this work, the Iosipescu sample coupon used for the determination of shear strength $\left(t_{13}\right)$ was similar to one proposed by Zhou et al. ${ }^{22}$. Thus dummy tabs (woven glass fiber prepregs) were bonded on the top and bottom of the composite laminate to make up the thickness for complete specimen. The specimens were machined down to the required dimensions. The V-notch $\left(90^{\circ}\right)$ was done by using a diamond-impregnated wheel until reach the carbon epoxy composite laminate.

Figure 2 shows the test specimen dimension for the Iosipescu test in the $\mathrm{S}_{13}$ direction. Five specimens were tested for each group (F and $\mathrm{G}$ ) and porosity level.

The Iosipescu shear strength is calculated by using Equation (3), where, $P$ is the failure load, $t$ is the thickness and $w_{\mathrm{n}}$ is the width between notches. The values for failure load are given in Newtons, and thickness and width are in millimeters.

$$
\text { Iosipescu Shear }(\mathrm{MPa})=\frac{P}{(t)\left(w_{n}\right)}
$$

Micrographs of the sample were obtained using a Reichert Jung microscope for void characterization and failure mode assessment.

\subsubsection{Mar-Lin criteria}

The Iosipescu and Interlaminar shear testing results were analyzed following the Mar-Lin approach ${ }^{17}$, and latter modified by Almeida ${ }^{11}$. The failure criteria proposed by Mar-Lin is based on the linear elastic fracture mechanics for homogeneous materials which takes into account the geometric characteristics of the defect, a slit crack or a small hole. In the case of composite laminates, the crack tip is at the fiber/matrix interface, and the singularity order $(m)$ is a function of fiber/matrix adhesion, shear modulus and Poisson ratio. The effect of voids in composites can be evaluated by Equation (4), where $\alpha$ is the ultrasonic absorption coefficient of the composite $\left(\mathrm{dB} \cdot \mathrm{mm}^{-1}\right)$ which is related to the void content in the composite and $H$ is the fracture toughness of the composite:

$$
\sigma_{f}=H(\alpha)^{-m}
$$

Typical values for singularity order $(m)$ for composites having voids are in the range of $0.10-0.35^{[7,11-12,16]}$. According to Costa et al. ${ }^{16}$,
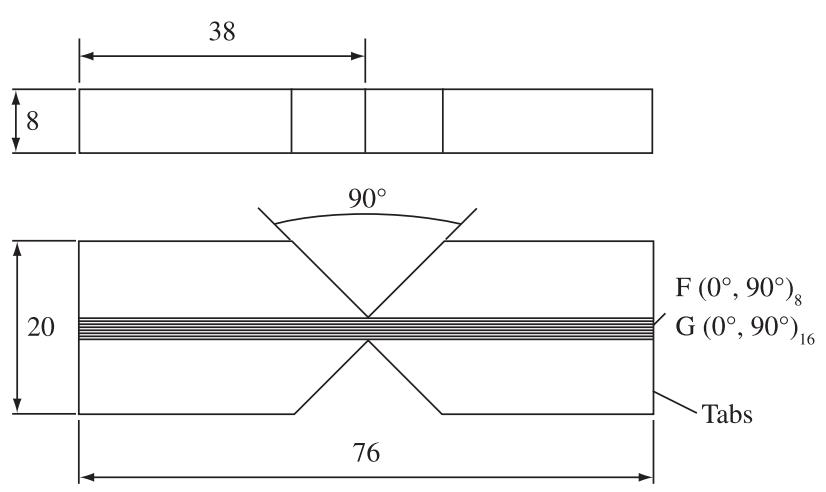

Figure 2. Iosipescu test coupon dimensions. the value of $m$ may be affected by material properties (i.e. Poisson and shear of fiber and matrix), shape and size of voids, fiber orientation, fiber volume content and number of layers. The Mar-Lin criteria states that below a critical attenuation coefficient $\left(\alpha_{\text {critic }}\right)$, that is related to a critical void volume fraction, the properties are unaffected by void presence (Equation 5). Thus,

$$
\sigma_{f}=\left\{\begin{array}{ll}
\sigma_{f 0} & \text { if } \alpha \leq \alpha_{\text {critic }} \\
H(\alpha)^{-m} & \text { if } \alpha \geq \alpha_{\text {critic }}
\end{array}\right\}
$$

where $\sigma_{\mathrm{f} 0}$ corresponds to the fracture stress of the composite containing the lowest volume fraction of voids. The $\alpha_{\text {critic }}$ can be calculated according to Equation (6).

$$
\log \alpha_{\text {critic }}=-\frac{1}{m} \log \left(\frac{\sigma_{f o}}{H}\right)
$$

The singularity order $(m)$ and the critical average attenuation coefficient $\alpha_{\text {crític }}$ are graphically obtained from the relation plotted in Figure 3 . The slope of the straight line is the singularity order. The projection of the intersection between lines $R$ and $S$ in the ordinate axis is the average critical attenuation coefficient. So, the fracture toughness $(H)$ can be calculated from Equation (6).

\section{Results and Discussion}

\subsection{Micrograph characterization}

The microstructural features of a composite are established during the curing process. Figure 4 shows a typical micrograph of a $\left(0^{\circ} / 90^{\circ}\right)_{8}$ composite laminate. The shape and size of voids are mainly influenced by where they are located. Voids (V) tends to be located in between fabric plies of the composite, near resin rich areas (R). Very small pores can also be present inside fiber bundles (B). In resin rich areas voids are bigger (macrovoids, 30-600 $\mu \mathrm{m}$ ) than the ones located at fiber bundles (microvoids, 7-30 $\mu \mathrm{m}$ ). Literature reports that composites can have a variety of shapes and sizes s, $^{4,14,16,23}$ and their distribution depends on fiber pattern. For instance, pores varying from 120 to $2000 \mu \mathrm{m}$ have been found in a carbon fiber/epoxy composite similar to the one used in this work ${ }^{4}$.

Figure 5 shows a typical micrograph of a $\left(0^{\circ} / 90^{\circ}\right)_{16}$ composite laminate. Despite the large number of pores, the features are similar to those found in the $\left(0^{\circ} / 90^{\circ}\right)_{8}$ laminate. In this case, it is clear that

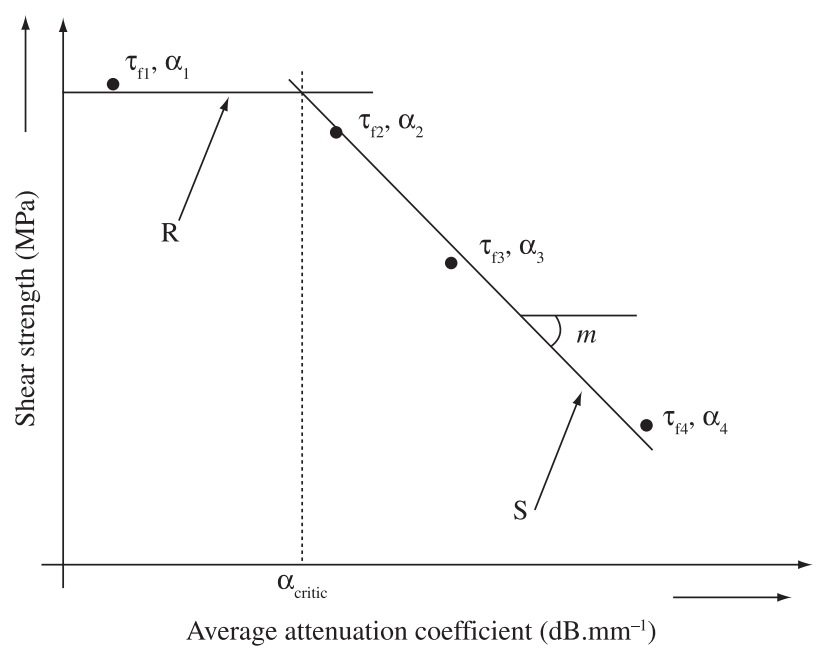

Figure 3. Determination of plot parameters according to the Mar-Lin criteria. 


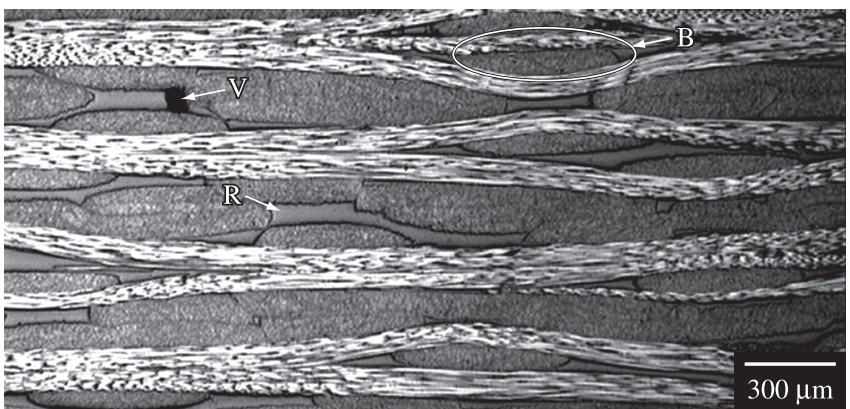

Figure 4. Typical cross-section of a $\left(0^{\circ} / 90^{\circ}\right)_{8}$ composite, void volume fraction of $0.31 \%$

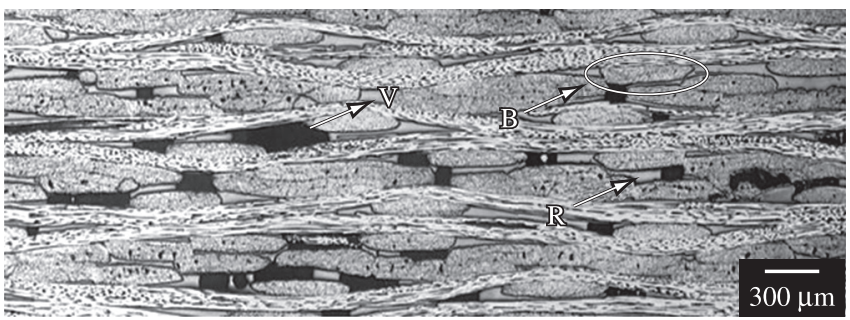

Figure 5. Typical cross-section of a $\left(0^{\circ} / 90^{\circ}\right)_{16}$ composite, void volume fraction of $7.06 \%$.

there is a non-homogenous void distribution throughout the whole composite thickness.

\subsection{Attenuation coefficient and void volume fraction}

Figure 6 shows the attenuation coefficient as a function of cure pressure representing all test panels manufactured for this study. Voids are clearly caused by variation of cure pressure during molding. In this work, the cure pressure in the autoclave was intentionally varied. In addition, the vacuum bag was sometimes vented at the beginning of the cure cycle. When the vacuum bag was not vented, compaction of the composite laminae was improved and porosity levels decreased.

An increase in pressure during cure leads to an exponential reduction in the attenuation coefficient, as a result of a better compaction of the plies. For cure pressures over $200 \mathrm{kPa}$ the attenuation coefficient tends to stabilize at $0.1 \mathrm{~dB} \cdot \mathrm{mm}^{-1}$, and the influence of the ventilation in the vacuum bag is no longer observed. The reduction in the attenuation coefficient is related to a reduction in the void volume fraction caused by a higher compaction of composite plies and an increase in cure pressure ${ }^{6,7}$.

Table 1 shows characteristics of the batches of the composites selected in this work. The composite panels chosen for testing took into account the levels of attenuation coefficient (i.e. porosity level) span from 0.26 to $2.10 \mathrm{~dB} \cdot \mathrm{mm}^{-1}$. Composites having lower attenuation coefficient were cured at pressures higher than $103 \mathrm{kPa}$ and the vacuum bag was not vented. Conversely, composites exhibiting higher attenuation coefficient were cured at pressures lower than $69 \mathrm{kPa}$ and the vacuum bag was vented.

Table 2 shows the characteristics of the carbon fiber/epoxy composites used in this work. Note that for a same level of void volume fraction, the $\left(0^{\circ}, 90^{\circ}\right)_{16}$ composite have a lower density than the $\left(0^{\circ}, 90^{\circ}\right)_{8}$ composite. The higher number of plies in the $\left(0^{\circ} / 90^{\circ}\right)_{16}$ composite created a barrier against resin bleeding during the molding cycle, leading to a reduction in density. The variation of the resin volume content may affect shear strength of composites, however, for this study the variation of resin volume content among the families is

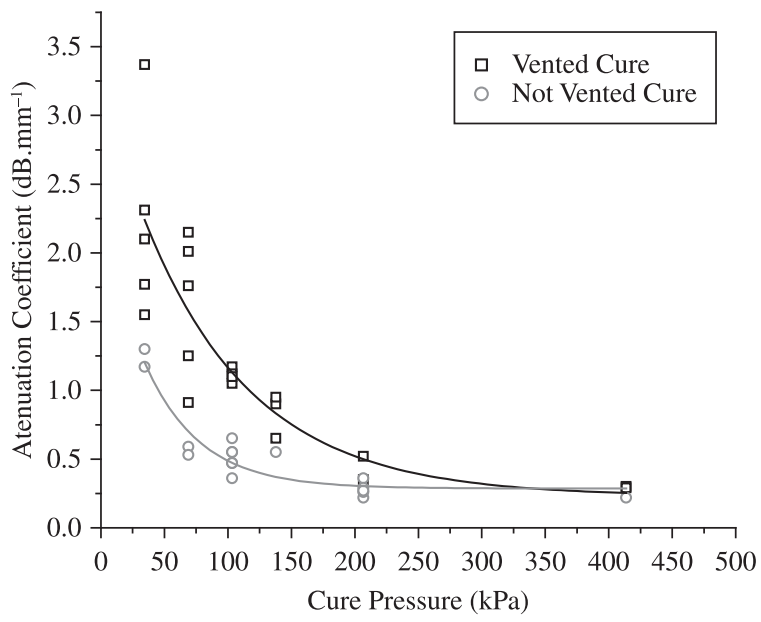

Figure 6. Medium attenuation coefficient as a function of cure pressure for carbon fiber/epoxy composites.

Table 1. Cure conditions for carbon fiber/epoxy composites and resulted average Attenuation Coefficient.

\begin{tabular}{cclc}
\hline Composite & $\begin{array}{c}\text { Cure pressure } \\
{[\mathrm{kPa}]}\end{array}$ & $\begin{array}{c}\text { Vacuum } \\
\text { bag }\end{array}$ & $\begin{array}{c}\text { Average coefficient of } \\
\text { attenuation }\left[\mathrm{dB} \cdot \mathrm{mm}^{-1}\right]\end{array}$ \\
\hline$\left(0^{\circ}, 90^{\circ}\right)_{8}$ & 207 & Not-vented & 0.26 \\
& 103 & Not-vented & 0.65 \\
& 69 & Vented & 1.25 \\
$\left(0^{\circ}, 90^{\circ}\right)_{16}$ & 207 & Vented & 2.10 \\
& 103 & Not-vented & 0.27 \\
& 69 & Vented & 0.50 \\
& 34 & Vented & 0.91 \\
& & & 1.77 \\
\hline
\end{tabular}

Table 2. Characteristics of the composite panels used in the work.

\begin{tabular}{ccccccc}
\hline \multirow{2}{*}{ Batch } & Composite & Density & Fiber Vol. & Resin Vol. & \multicolumn{2}{c}{ Voids } \\
\cline { 3 - 7 } & & $\left(\right.$ g.cm $\left.^{-3}\right)$ & $($ vol. $(\%))$ & $($ vol. $(\%))$ & $(\%)$ \\
\hline 1 & $\left(0^{\circ}, 90^{\circ}\right)_{8}$ & 1.54 & 58.71 & 40.98 & 0.31 & \pm 0.14 \\
2 & $\left(0^{\circ}, 90^{\circ}\right)_{8}$ & 1.50 & 58.43 & 38.61 & 2.96 & \pm 0.19 \\
3 & $\left(0^{\circ}, 90^{\circ}\right)_{8}$ & 1.44 & 56.06 & 36.98 & 6.96 & \pm 0.10 \\
4 & $\left(0^{\circ}, 90^{\circ}\right)_{8}$ & 1.41 & 55.16 & 36.10 & 8.83 & \pm 0.05 \\
1 & $\left(0^{\circ}, 90^{\circ}\right)_{16}$ & 1.52 & 56.49 & 43.15 & 0.36 & \pm 0.07 \\
2 & $\left(0^{\circ}, 90^{\circ}\right)_{16}$ & 1.49 & 55.72 & 41.58 & 2.71 & \pm 0.45 \\
3 & $\left(0^{\circ}, 90^{\circ}\right)_{16}$ & 1.47 & 55.37 & 40.65 & 3.98 & \pm 0.35 \\
4 & $\left(0^{\circ}, 90^{\circ}\right)_{16}$ & 1.43 & 54.69 & 38.25 & 7.06 & \pm 0.23 \\
\hline
\end{tabular}

considered within an acceptable range for most aeronautical composite materials (considering raw material and process variability).

Figure 7 shows a correlation between attenuation coefficient and void volume fraction. The fiber volume fraction and resin volume fraction were determined through acid digestion, from which the void volume fraction is calculated. Minor variations are expected due to the interaction between the void shape and ultrasound, as well as size and distribution of void throughout the composite ${ }^{9,12,16}$.

\subsection{Interlaminar shear, iosipescu shear and Mar-Lin criteria}

Results for Interlaminar shear strength and Iosipescu shear strength for the $\mathrm{F}\left(0^{\circ} / 90^{\circ}\right)_{8}$ and $\mathrm{G}\left(0^{\circ} / 90^{\circ}\right)_{16}$ groups of composite 


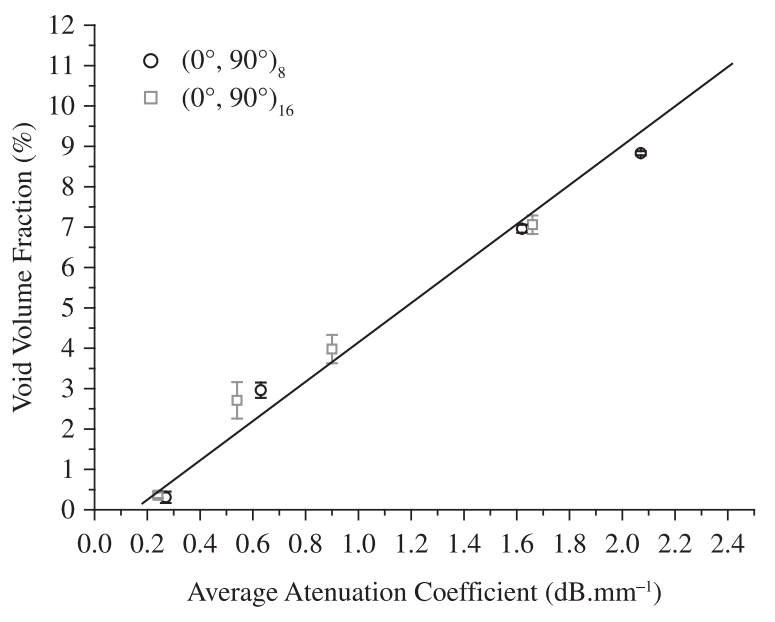

Figure 7. Average attenuation coefficient as a function of void volume fraction for $\left(0^{\circ} / 90^{\circ}\right)_{8}$ and $\left(0^{\circ} / 90^{\circ}\right)_{16}$ composites.

Table 3. Results for interlaminar shear and iosipescu shear strength for composites $\left(0^{\circ} / 90^{\circ}\right)_{8}$ and $\left(0^{\circ} / 90^{\circ}\right)_{16}$.

\begin{tabular}{ccccc}
\hline Batch & Composite & Voids $(\%)$ & $\begin{array}{c}\text { Interlaminar } \\
\text { Shear }(\mathrm{MPa})\end{array}$ & $\begin{array}{c}\text { Iosipescu } \\
\text { Shear }(\mathrm{MPa})\end{array}$ \\
\hline 1 & $\left(0^{\circ} / 90^{\circ}\right)_{8}$ & $0.31 \pm 0.14$ & $71.54 \pm 6.18$ & $67.16 \pm 3.04$ \\
2 & $\left(0^{\circ} / 90^{\circ}\right)_{8}$ & $2.96 \pm 0.19$ & $68.74 \pm 1.41$ & $62.76 \pm 1.73$ \\
3 & $\left(0^{\circ} / 90^{\circ}\right)_{8}$ & $6.96 \pm 0.10$ & $55.03 \pm 1.23$ & $58.31 \pm 1.71$ \\
4 & $\left(0^{\circ} / 90^{\circ}\right)_{8}$ & $8.83 \pm 0.05$ & $51.60 \pm 1.79$ & $56.27 \pm 3.46$ \\
1 & $\left(0^{\circ} / 90^{\circ}\right)_{16}$ & $0.36 \pm 0.07$ & $69.08 \pm 3.04$ & $65.72 \pm 1.70$ \\
2 & $\left(0^{\circ} / 90^{\circ}\right)_{16}$ & $2.71 \pm 0.45$ & $60.60 \pm 1.64$ & $62.90 \pm 3.22$ \\
3 & $\left(0^{\circ} / 90^{\circ}\right)_{16}$ & $3.98 \pm 0.35$ & $58.95 \pm 1.68$ & $61.28 \pm 3.29$ \\
4 & $\left(0^{\circ} / 90^{\circ}\right)_{16}$ & $7.06 \pm 0.23$ & $50.12 \pm 1.29$ & $53.67 \pm 1.20$ \\
\hline
\end{tabular}

laminates are shown in Table 3. Interlaminar shear strength decreases as the void volume fraction increases for both composite thicknesses. Interlaminar shear strength is around $70 \mathrm{MPa}$ for composites having void volume fraction lower than $0.5 \%$ and reach values as low as $50 \mathrm{MPa}$ for void volume fraction near $9 \%$. This corresponds to a $26 \%$ reduction in shear strength when porosity levels rise $8 \%$. Trends in the results for both Interlaminar and Iosipescu shear are similar. However, the reduction in the Iosipescu shear strength for a same level of void volume fraction is lower than for the Interlaminar shear strength. For instance, composites having around $8 \%$ void volume fraction lowered their Interlaminar shear at about $26 \%$ in relation to the standard composite, while the Iosipescu shear is lowered only $\sim 16 \%$ for the same porosity drop. Although both test methods promote shear loads to the specimens, the differences in the shear strength when comparing the test methods may be attributed to the form of load application and void distribution across the test specimen. Iosipescu test method promotes pure shear and a mutual displacement of the plies, while Interlaminar shear test flexural loads may be associated with shear loads at central line plies.

The Figure 8 shows a plot for the Interlaminar shear strength as a function of average attenuation coefficient. The value of the critical attenuation coefficient $\left(\alpha_{\text {critic }}\right)$ was determined by the Mar-Lin criteria $^{11,17}$, in which the degree of sensitivity to voids, represented by singularity order $\mathrm{m}$, and the toughness $(\mathrm{H})$ for the composites were found. The degree of sensitivity to voids depends on the shear modulus of the composite, the Poisson ratio of the fiber $(\sim 0.18$ for carbon fiber) and the Poisson ratio of the matrix ( 0.35 for epoxy resin $)^{17}$. If the failure occurs in the matrix, the degree of sensitivity
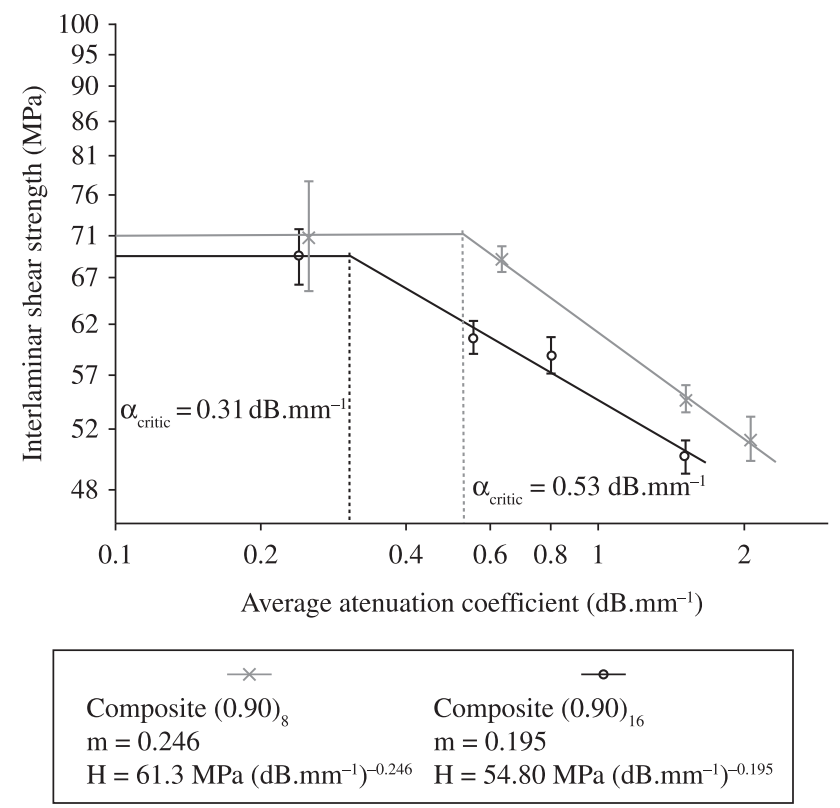

Figure 8. Interlaminar shear strength as a function of average attenuation coefficient for composites $\left(0^{\circ} / 90^{\circ}\right)_{8}$ and $\left(0^{\circ} / 90^{\circ}\right)_{16}$.

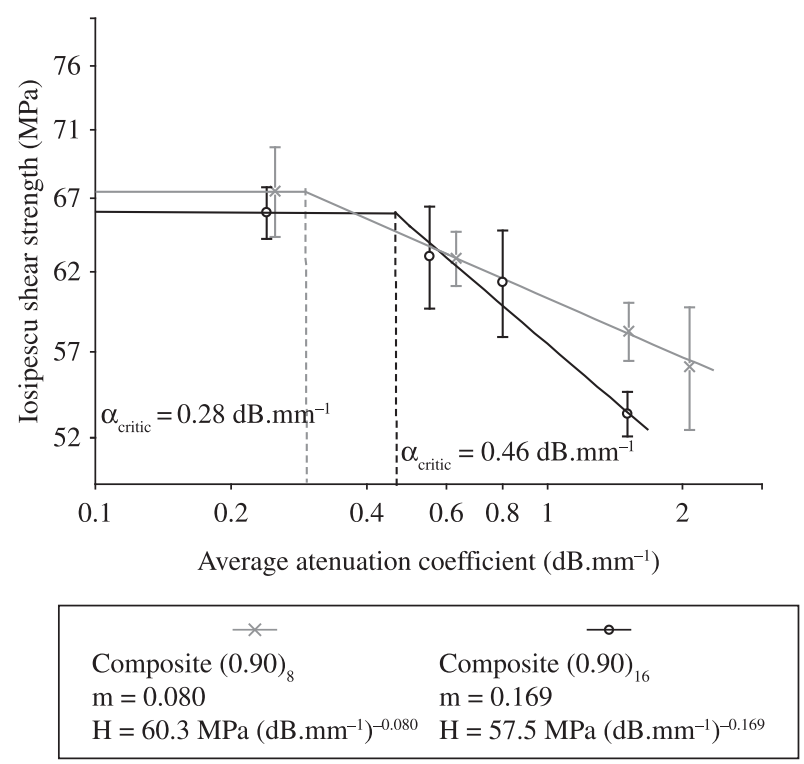

Figure 9. Iosipescu shear strength as a function of average attenuation coefficient for composites $\left(0^{\circ} / 90^{\circ}\right)_{8}$ and $\left(0^{\circ} / 90^{\circ}\right)_{16}$.

has a value between 0 and $0.5^{[12,24]}$. For the $\left(0^{\circ} / 90^{\circ}\right)_{8}$ specimens, the toughness $(H)$ was $61.3 \mathrm{MPa}\left(\mathrm{dB} \cdot \mathrm{mm}^{-1}\right)^{-0.246}$, and the singularity order $(m)$, was 0.246 and the average critical attenuation coefficient $\left(\alpha_{\text {critic }}\right)$ was $0.53 \mathrm{~dB} \cdot \mathrm{mm}^{-1}$, that represents about $1.89 \%$ of void volume fraction. For the $\left(0^{\circ} / 90^{\circ}\right)_{16}$ specimens, the toughness $(H)$ was $54.8 \mathrm{MPa}$ $\left(\mathrm{dB} . \mathrm{mm}^{-1}\right)^{-0.195}$, the sensibility to voids $(m)$ was 0.195 and the average critical attenuation coefficient $\left(\alpha_{\text {critic }}\right)$ was $0.31 \mathrm{~dB} \cdot \mathrm{mm}^{-1}$ (i.e. $0.85 \%$ of void volume fraction). These dissimilarities are mainly attributable to differences in distribution of pores in the composite $\left(0^{\circ} / 90^{\circ}\right)_{16}$ and differences in the fiber volume fraction in relation to the $\left(0^{\circ} / 90^{\circ}\right)_{8}$ composite, since the shear modulus and Poisson ratio for both, although not measured, are expected to be similar as they are the same material. The literature reports experimental values of the singularity order for Interlaminar shear in the range of 0.16 to $0.30^{12,11}$. Costa ${ }^{16}$ 
Table 4. Summary of results according to the Mar-Lin criteria for Interlaminar shear and Iosipescu shear loading for composites $\left(0^{\circ}, 90^{\circ}\right)_{8}$ and $\left(0^{\circ} / 90^{\circ}\right)_{16}{ }^{\circ}$

\begin{tabular}{lcccc}
\hline \multicolumn{1}{c}{ Composite } & Toughness & Singularity & $\begin{array}{c}\text { Average critical } \\
\text { attenuation coefficient }\end{array}$ & $\begin{array}{c}\text { Critical void } \\
\text { volume fraction }\end{array}$ \\
\cline { 2 - 5 } & $\mathrm{MPa}\left(\mathrm{dB} \cdot \mathrm{mm}^{-1}\right)^{\mathrm{m}}$ & order & $\left(\mathrm{dB} . \mathrm{mm}^{-1}\right)$ & $(\%)$ \\
\hline IOSIPESCU $\left(0^{\circ} / 90^{\circ}\right)_{8}$ & 60.30 & 0.080 & 0.29 & 0.74 \\
IOSIPESCU $\left(0^{\circ} / 90^{\circ}\right)_{16}$ & 57.50 & 0.169 & 0.46 & 1.53 \\
INTERLAMINAR $\left(0^{\circ} / 90^{\circ}\right)_{8}$ & 61.30 & 0.246 & 0.53 & 1.89 \\
INTERLAMINAR $\left(0^{\circ} / 90^{\circ}\right)_{16}$ & 54.80 & 0.195 & 0.31 & 0.85 \\
\hline
\end{tabular}

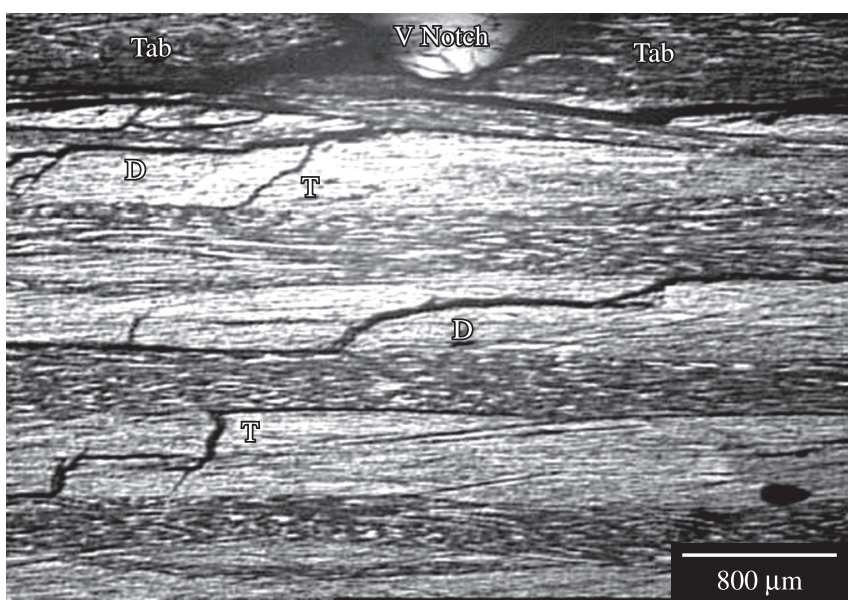

Figure 10. Micrograph near the V-notch Iosipescu coupon showing the typical failure pattern of the $\left(0^{\circ} / 90^{\circ}\right)_{16}$ composite. Initial fiber void fraction of $0.36 \%$

obtained a value of 0,17 for a unidirectional carbon/epoxy composite while $\mathrm{Gou}^{8}$ obtained for a similar material $\mathrm{m}=0.364^{[8]}$.

The Figure 9 shows a plot for the Iosipescu shear strength as a function of average attenuation coefficient. For the $\left(0^{\circ} / 90^{\circ}\right)_{8}$ specimens, the fracture toughness $(H)$ was $60.3 \mathrm{MPa}\left(\mathrm{dB} \cdot \mathrm{mm}^{-1}\right)^{-0.080}$ and the average critical attenuation coefficient $\left(\alpha_{\text {critic }}\right)$ was $0.28 \mathrm{~dB} \cdot \mathrm{mm}^{-1}$, which corresponds to a void volume fraction of $\sim 0.74 \%$. The singularity order $(m)$ in this case was 0.080 . For the $\left(0^{\circ} / 90^{\circ}\right)_{16}$ specimens, the $H$ was $57.5 \mathrm{MPa}\left(\mathrm{dB} . \mathrm{mm}^{-1}\right)^{-0.169}$ and the $\alpha_{\text {critic }}$ was $0.46 \mathrm{~dB} . \mathrm{mm}^{-1}$, which corresponds to a void volume fraction of $\sim 1.53 \%$. The singularity order was 0.169 . These results show that for similar composite stacking sequence, the $\alpha_{\text {critic }}$ is higher for the thicker laminate, i.e., the limit of critical porosity $\left(\alpha_{\text {critic }}\right)$, where shear properties are unaffected. But, once this limit is surpassed, every increase in void content leads to a more pronounced reduction in Iosipescu shear strength. Table 4 summarizes the results for $\left(0^{\circ} / 90^{\circ}\right)_{8}$ and $\left(0^{\circ} / 90^{\circ}\right)_{16}$ composites under Interlaminar shear and Iosipescu shear loading.

The differences in the singularity order $(m)$ are attributed to the type of shear loading for the test coupons and also by the void distribution. During the Interlaminar shear loading the well known main failure mode occurs at about the central line of the composites. According to Jeong ${ }^{12}$, this is where most of porosity is located and where small slit-like cracks can be seen. The failure mode in the case of Iosipescu shear test occurs by a mutual shear deformation in between all plies of the composite, by the effect of shear force, which results in a lower sensitivity to voids.

Figure 10 shows a micrograph of the failure mode for the Iosipescu coupon, near the $90^{\circ}$ notch. It can be seen that failure occurs mainly by delamination between plies at (D) and predominantly at an angle of $45^{\circ}$ to the loading direction. Cracks (T) are mainly through the fiber bundles linking delaminated plies. The starting point for crack propagation is at the notch root which is consistent with reported failure modes for this test in literature ${ }^{21-22}$

\section{Conclusion}

Carbon fiber/epoxy composites were manufactured with different levels of porosity. The shape and size of the voids varied throughout the material. They are either elliptic and large, having size of 30-600 $\mu \mathrm{m}$ (macropores), or cylindrical and small, having size of 7-30 $\mu \mathrm{m}$ (micropores). Large pores are located mainly in resin rich regions, mainly weft/fill crossovers, while small pores are located mainly inside fiber bundles.

Micropores tend to occur in higher quantities when the void volume fraction is higher than $2 \%$ and they occur randomly. For void volume fraction lower than $0.5 \%$, the Iosipescu shear strength was 65-67 MPa, and the Interlaminar shear strength was 69-71 MPa.

Porosity lowers the shear strength of composites, although the Iosipescu method is more conservative compared to the Interlaminar shear test. A reduction of $\sim 16 \%$ in the Iosipescu shear was found for a carbon fiber/epoxy composite having $\sim 8 \%$ void volume fraction. On the other hand, a reduction of $\sim 26 \%$ in Interlaminar shear strength was found for composites having the same $\sim 8 \%$ void volume fraction.

The Mar-Lin criterion helps to evaluate the limits of acceptable porosity in composite materials. The Mar-Lin criteria showed that singularity order, i.e., the sensibility to voids in composites are a function of the loading and type of testing and also is influenced by the void distribution and localization. The loading mode of shear testing shows that void sensibility of composites is lower in the Iosipescu shear $(\mathrm{m}=0.08-0.16)$ when compared to Interlaminar shear (0.19-0.24) for similar void volume fraction.

\section{Acknowledgements}

The research is part of a collaborative work of the Aeronautical Institute of Technology and the Sandia National Laboratories. The authors express their gratitude to the State of São Paulo Research Foundation (Fapesp) process $n^{\circ} 2007 / 55190-8$ and the National Council for Scientific and Technological Development (CNPq). The authors would also like to thank the Materials Division/AMR/IAE/ CTA for their help in the mechanical tests and the Embraer for their support.

\section{References}

1. ASM International. Engineered Materials Handbook: Composites. Ohio, USA: ASM International; 1987. vol. 1.

2. Daniel IM and Ishai O. Engineering Mechanics of Composite Materials. New York: Oxford University Press; 1994.

3. Society of Manufacturing Engineers. Composite Applications: The Future is now. fisrt ed. Dearborn, Michigan: SME; 1989. p. 135-148.

4. Rubin AM and Jerina KL. Evaluation of Porosity in Composite Aircraft Structures. Composites Engineering. 1993; 3(7-8):601-618. 
5. Bowles KJ and Frimpong S. Voids Effects on the Interlaminar Shear Strength of Unidirectional Graphite-Fiber-Reinforced Composites. Journal of Composite Materials. 1992 ; 26(10):1487-1509.

6. Tang J, Lee WI and Springer GS. Effects of Cure Pressure on Resin Flow, Voids, and Mechanical Properties. Journal of Composite Materials. 1987; 21(5):421-440

7. Liu L, Zhang B, Wang D and Wu Z. Effects of Cure Cycles on Void Content and Mechanical Properties of Composites Laminates. Composite Structures. 2006; 73:303-309.

8. Guo Z, Liu L, Zhang B and Du S. Critical Void Content for Thermoset Composite Laminates. Journal of Composite Materials. 2009; 43(17):1775-1790.

9. Stone DEW and Clarke B. Ultrasonic Attenuation as a Measure of void Content in Carbon-Fibre Reinforced Plastics. Non-Destructive Testing. 1975; 8(3):137-145.

10. Hsu DK. Ultrasonic Measurements of Porosity in woven Graphite Polyimide Composites. Review of Progress in Quantitative Non Destructive Evaluation. 1988; 7B:1063-1068.

11. Almeida SFM and Nogueira Neto ZS. Effect of Void Content on the Strength of Composite Laminates. Composite Structures. 1994; 28(2):139-148.

12. Jeong H. Effects of voids on the Mechanical Strength and Ultrasonic Attenuation of Laminated Composites. Journal of Composite Materials. 1997; 31(3):277-292.

13. ASTM. Standard Test Methods for Constituent Content of Composite Materials . ASTM D3171-06. West Conshohoken, United States: American Society for Testing and Materials; 2006.

14. Paciornik S and D'Almeida JRM. Measurement of Void Content and Distribution in Composite Materials through Digital Microscopy. Journal of Composite Materials. 2009; 43(2):101-112.

15. Kohn EJ, Sands AG and Clark RC. Quantitative Measurement of Void Content in Glass Filament Wound Composites and the Correlation of
Interlaminar Shear Strength with Void Content. Industrial \& Engineering Chemistry Product Research and Development. 1973; 7(3):179.

16. Costa ML, Almeida SFM and Rezende MC. The Influence of Porosity on the Interlaminar Shear Strength of Carbon/Epoxy and Carbon/ Bismaleimide Fabric Laminates. Composites Science and Technology. 2001; 61(14):2101-2108.

17. Mar JW and Lin KY. Fracture Mechanics Correlation for Tensile Failure of Filamentary Composites with Holes. Journal of Aircraft. 1977; 14(7):703-704.

18. Walker TH, Avery WB, Ilcewicz LB, Poe Jr. CC and Harris CE. Tension Fracture of Laminates for Transport Fuselage - Part I: Material Screening. Second NASA Advanced Technology Conference. 1992; NASA CP3154:197-238.

19. Walker TH, Ilcewicz LB, Polland DR and Poe Jr. CC. Tension fracture of laminates for transport fuselage. Part 2: Large notches. Third NASA Advanced Composites Technology Conference. 1993; NASA CP3178:727-758.

20. ASTM. Standard Test Method for Short-Beam Strength of Polymer Matrix Composite Materials and Their Laminates. ASTM D2344. West Conshohoken, United States: American Society for Testing and Materials; 2006.

21. ASTM. Standard Test Method for Shear Properties of Composite Materials by the V-Nocthed Beam Method. ASTM D5379-05. West Conshohoken, United States: American Society for Testing and Materials; 2005.

22. Zhou G, Green ER and Morrison C. In-plane and Interlaminar Shear Properties of Carbon/Epoxy Laminates. Composites Science and Technology. 1995; 55(2):187-193.

23. Wu Y, Shivpuri R and Lee LJ. Effect of Macro and Micro Voids on Elastic Properties of Polymer Composites. Journal of Reinforced Plastics and Composites. 1998; 17(15):1391-1402.

24. Zak AR and Willians ML. Crack Point Singularities at a Bi-Material Interface. Journal of Applied Mechanics. 1963; 85(E): 142-143. 
